\title{
Effect of the Length of Alkyl Side Chains in the Electronic Structure of Conjugated Polymers
}

\author{
Eliezer Fernando Oliveira ${ }^{a}$, Francisco Carlos Lavarda ${ }^{a, b *}$ \\ ${ }^{a}$ Programa de Pós-Graduação em Ciência e Tecnologia de Materiais - POSMAT, \\ Universidade Estadual Paulista - UNESP, Bauru, SP, Brazil \\ ${ }^{b}$ Departamento de Física, Faculdade de Ciências, Universidade Estadual Paulista - UNESP, \\ Av. Eng. Luiz Edmundo Carrijo Coube, 14-01, CEP 17033-360, Bauru, SP, Brazil
}

Received: March 6, 2014; Revised: July 8, 2014

\begin{abstract}
Computational modeling studies of conjugated polymers have been shown to present many challenges. One such challenge is to find ways to reduce the computational cost for these studies without compromising the quality of the results. An approach longly used in the literature for this purpose is replacing long alkyl side chains (with six or more carbons) with a methyl group. This work reports on a theoretical study conducted with the conjugated polymer poly(3-hexylthiophene), which contains a hexyl side chain attached to the monomer, to verify the influence of the size of the alkyl side chain on its electronic structure. The results indicated that, for polymers containing long alkyl side chains, replacement with a propyl group offered full saturation of all properties under review, showing it to be a good approach.
\end{abstract}

Keywords: computer modeling, conjugated polymers, electronic structure calculation, poly(3-hexylthiophene), P3HT, exciton binding energy

\section{Introduction}

Nowadays, there is great interest in the use of organic materials in electronic devices ${ }^{1,2}$. Of these, the class of conjugated polymers has been the subject of intense study, mainly because of their potential for employment in the active layers of organic solar cells ${ }^{1-7}$. These materials have several advantages compared to their inorganic counterparts, for example, low cost of raw materials and easy processing. However, because of deficiencies in their intrinsic properties, they continue to be the subject of many theoretical and experimental studies aimed at discovering improvements that will make them more attractive and useful for technological applications ${ }^{1,2}$.

Molecular modeling of conjugated polymers has been a challenge for the scientific community for several reasons, for example, the fact that they are large molecules and thus easily deformable and the presence of side chains ${ }^{2}$. Several theoretical studies of these materials have been conducted based on quantum or classical mechanics ${ }^{8-13}$, but the number of variables that must be taken into account in any model carries a high computational cost ${ }^{8}$. Thus, it is necessary to find ways to reduce this cost to simulate these materials without compromising the quality of results.

One approach to reducing the computational costs in studies of conjugated polymers is the use of oligomers ${ }^{14,15}$, in which the properties of the polymers are theoretically estimated by extrapolating data obtained for the oligomers. This approach has been shown to yield very efficient results, compared with experimental ones ${ }^{14-16}$. However, the computational cost is not significantly reduced, because

*e-mail: lavarda@fc.unesp.br many of the polymers currently employed have monomeric units with long and complex side chains, which hinders the conformational search for them ${ }^{8}$.

In conjunction with the oligomers approach, a simplification has been developed for polymers that have long alkyl side chains (having six or more carbons). These side chains are replaced by a methyl group ${ }^{17,18}$, so that the conformational search becomes easier. However, it is known from literature that the size of the alkyl side chains can influence the structural conformation and electronic properties of polymers ${ }^{8,19}$. This suggests that replacing an long alkyl side chain with a methyl group can be a risky approach, which could compromise the results obtained for theoretical studies of conjugated polymers.

We therefore conducted a theoretical study with the aim of determining the influence of the length of the alkyl side chain on the electronic structure of conjugated polymers. We also tried to discover whether there might be a characteristic length of the side chains at which the electronic properties would remain unchanged; this might be suitable for use as a modeling approach. We chose to study poly(3-hexylthiophene) (P3HT), a polymer widely used in

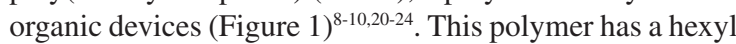
side chain in each monomer unit. The results indicated that the size of the side chains adopted influenced the electronic structure of P3HT, up to propyl size.

\section{Calculation Procedures}

To conduct this study, we adopted the oligomers approach, employing $\mathrm{P} 3 \mathrm{HT}$ oligomers ranging from two 
to six monomeric units. To verify the effect of the size of the alkyl side chain, we studied the oligomers with ramifications ranging from methyl to hexyl, the actual size of the ramifications of $\mathrm{P} 3 \mathrm{HT}$.

To obtain the oligomers for our study, we employed an optimized geometrical structure by a semiempirical method and electronic structure data from density functional theory (DFT) calculations ${ }^{25}$. This approach has been applied with satisfactory results in studies of conjugated polymers ${ }^{8,9,16}$, and is feasible owing to the size of the systems studied here, as well as the number of conformers analyzed. The exclusive use of ab-initio methods would result in considerable computational cost. We adopted fully coplanar polymeric structures, as expected in the solid state ${ }^{1,10,14,16}$, and the alkyl branches were initially predisposed in an antiperiplanar conformation, as we had predicted in previous studies to be the most likely ${ }^{8,9}$.

All studied structures were optimized by the HartreeFock semiempirical Parametric Method 6 (PM6) $^{26}$ implemented in the computational package MOPAC2012 ${ }^{27}$. We chose PM6 because of its satisfactory performance in studies with polythiophene derivatives ${ }^{8,9,16,28,29}$. The geometry optimization process was considered completed when the gradient norm drops below $0.01 \mathrm{kcal}^{\mathrm{mol}} \mathrm{m}^{-1} / \AA$. After geometrical optimizations, we obtained the electronic structure data of oligomers through DFT calculations with the hybrid functional B3LYP ${ }^{30}$ on GAMESS software ${ }^{31}$. The basis functions set chosen was $6-31 \mathrm{G}(1 \mathrm{~d})^{32}$. The self consistent field electronic structure was considered converged when the energy of two cycles changes by less than $10^{-5}$ Hartree. The DFT/B3LYP/6-31G(1d) methodology has been widely employed in studies of conjugated polymers, where it has been shown to yield good results ${ }^{14,16,28}$. We analyzed the data for the lowest unoccupied and highest occupied molecular orbitals energy (LUMO and HOMO, respectively) and the energy gap between LUMO and $\mathrm{HOMO}\left(\mathrm{E}_{\mathrm{g}}\right)$. All calculations were performed in vacuum.

As well as evaluating data on the electronic structure of the oligomers in side chains with variable sizes, we also evaluated the exciton binding energy $\left(\mathrm{E}_{\mathrm{b}}\right)$, one of the parameters that govern charge generation in materials used in organic electronics ${ }^{33}$. $\mathrm{E}_{\mathrm{b}}$ can be estimated as the difference between $\mathrm{E}_{\mathrm{g}}$ and the vertical transition energy from the ground state to first dipole-allowed excited state $\left(\mathrm{E}_{\text {vert }}\right)$, i.e., $\mathrm{E}_{\mathrm{b}}=\mathrm{E}_{\mathrm{g}}-\mathrm{E}_{\mathrm{vert}}{ }^{34,35}$. Such data can be obtained by calculation of electronic structure. In order to observe the influence of the alkyl side chain size in $\mathrm{E}_{\mathrm{b}}$, we calculated this property only for the largest structures studied, with six monomer units. We performed the calculations for $\mathrm{E}_{\text {vert }}$ by two methods: the semiempirical method ZINDO/S ${ }^{36,37}$, coupled with the Configuration Interaction with Single Excitations (CIS) method $^{38,39}$, using computational package ORCA ${ }^{40}$, and the Time-Dependent Density Functional Theory (TD-DFT) ${ }^{41}$, with the same functional and basis set described above, used in computational package GAMESS. We calculated ten transitions (roots) for each oligomer under consideration, including only transitions between singlet states.

For the extrapolation of the HOMO, LUMO, and $\mathrm{E}_{\mathrm{g}}$ values, various fitting methods are reported in the literature. The most popular are $\mathrm{Kuhn}^{14,18}$, Meier ${ }^{8,9,42}$, linear ${ }^{34}$, and polynomial $^{12,15}$. However, it should be noted that, in studies conducted with oligomers with up to eight monomer units, the use of linear or polynomial fitting in relation to the inverse quantity of monomeric units $(1 / \mathrm{n})$ produced reasonable results ${ }^{15,34}$. Thus, for our extrapolations, we adopted linear fits.

\section{Results and Discussion}

We present the extrapolated results obtained for the electronic structure of P3HT with side chains ranging from methyl to hexyl in Table 1. The experimental results for HOMO, LUMO, and $\mathrm{E}_{\mathrm{g}}$ values of $\mathrm{P} 3 \mathrm{HT}$ are respectively $-4.6 \mathrm{eV},-2.7 \mathrm{eV}$, and $1.9 \mathrm{eV}^{43}$. Thus, we also present in Table 1 the deviations obtained in the calculations for such properties. Figure 2 presents graphs of the extrapolations made.

It is already known from the literature on polymer modeling studies that the use of the DFT with B3LYP functional shows the best results for electronic properties. Using this methodology, the values for HOMO and $\mathrm{E}_{\mathrm{g}}$ exhibit deviations up to $10 \%$ compared to the experimental values, regardless of the fitting method employed for the extrapolations ${ }^{15,44}$. For the LUMO, deviations of up to $1 \mathrm{eV}$ can be observed; as these orbitals are not occupied (first virtual orbital), the lack of electrons and the self-consistent field solution for the system's wave function are the main reasons suggested for discrepancies between the calculated and experimental values ${ }^{44}$. Therefore, the deviations found

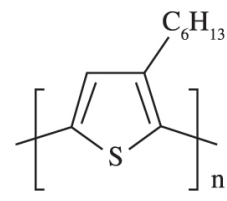

Figure 1. Structural formula of P3HT.

Table 1. Extrapolated values obtained for electronic structure data of P3HT with different side chains.

\begin{tabular}{ccccccc}
\hline Side Chain Type & HOMO $(\mathbf{e V})$ & $\begin{array}{c}\text { HOMO } \\
\text { Deviation }(\boldsymbol{\%})\end{array}$ & LUMO $(\mathbf{e V})$ & $\begin{array}{c}\text { LUMO } \\
\text { Deviation }(\boldsymbol{\%})\end{array}$ & $\mathbf{E}_{\mathrm{g}}(\mathbf{e V})$ & $\begin{array}{c}\mathbf{E}_{\mathrm{g}} \text { Deviation } \\
(\boldsymbol{\%})\end{array}$ \\
\hline Methyl & -4.21 & 8.47 & -2.23 & 17.41 & 1.97 & 3.68 \\
Ethyl & -4.27 & 7.17 & -2.27 & 15.92 & 2.00 & 5.26 \\
Propyl & -4.24 & 8.04 & -2.24 & 17.04 & 1.99 & 4.73 \\
Butyl & -4.24 & 8.04 & -2.24 & 17.04 & 1.99 & 4.73 \\
Pentyl & -4.24 & 7.82 & -2.24 & 17.04 & 1.99 & 4.73 \\
Hexyl & -4.24 & 7.82 & -2.24 & 17.04 & 1.99 & 4.73 \\
\hline
\end{tabular}




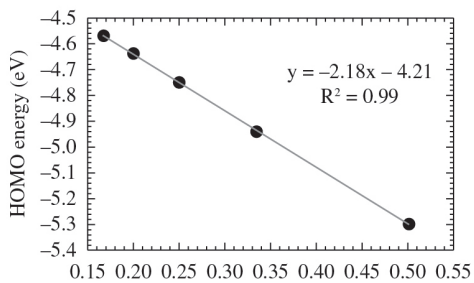

$1 / \mathrm{n}$

(a)

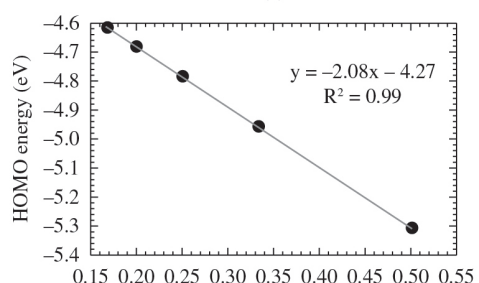

$1 / n$

(d)

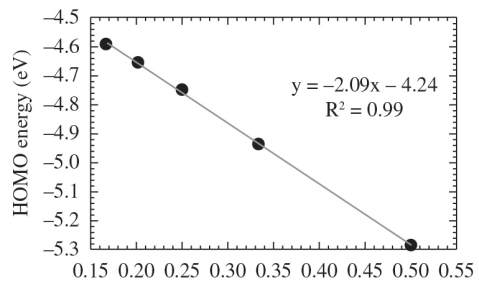

$1 / n$

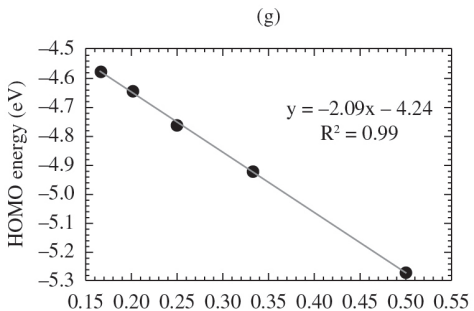

$1 / \mathrm{n}$

(j)

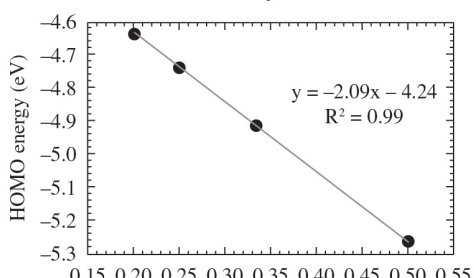

$1 / \mathrm{n}$

(m)

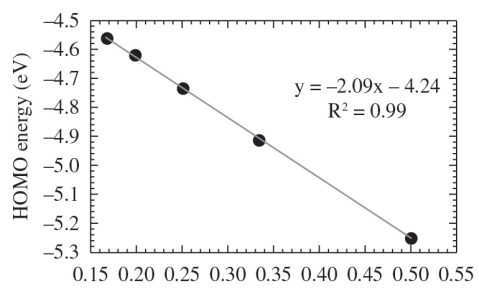

$1 / \mathrm{n}$

(p)

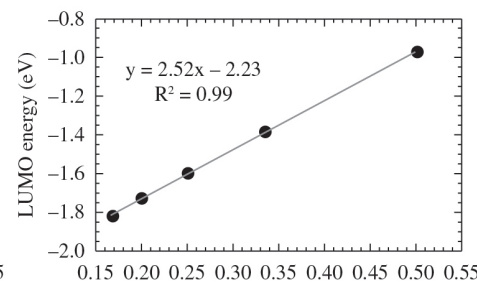

$1 / \mathrm{n}$

(b)

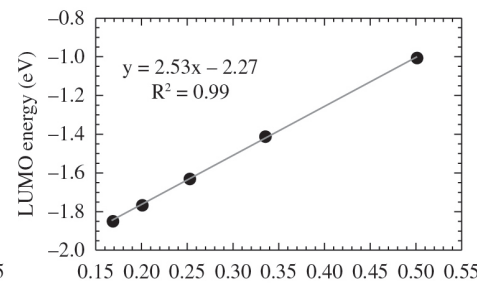

$1 / \mathrm{n}$

(e)

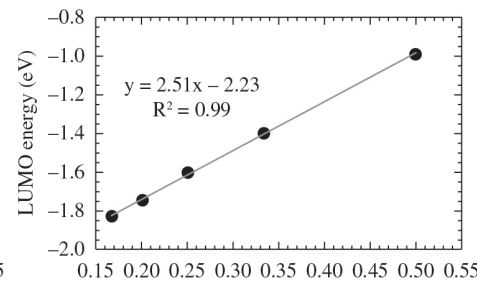

$1 / \mathrm{n}$

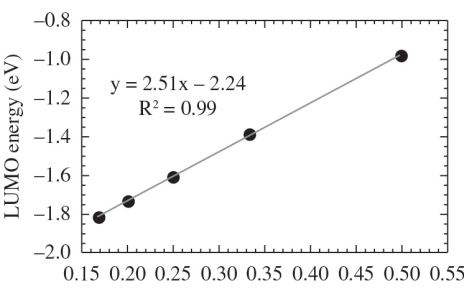

$1 / \mathrm{n}$

(k)

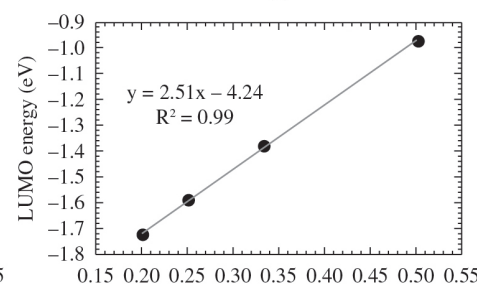

$1 / \mathrm{n}$

(n)

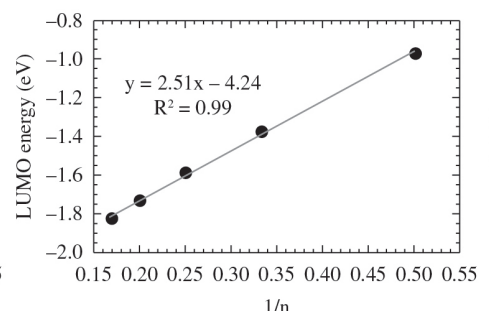

$1 / \mathrm{n}$

(q)

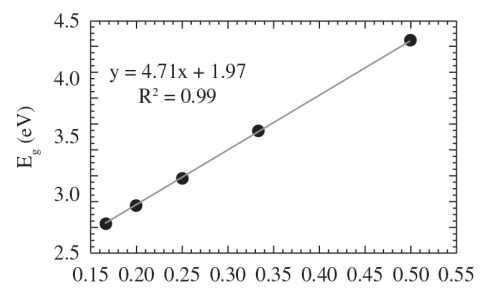

$1 / \mathrm{n}$

(c)

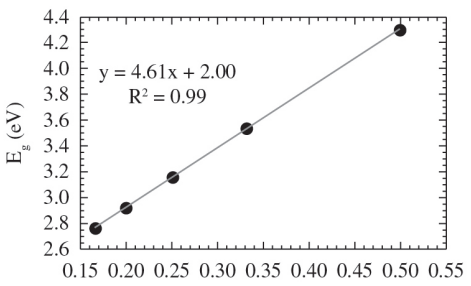

$1 / \mathrm{n}$

(f)

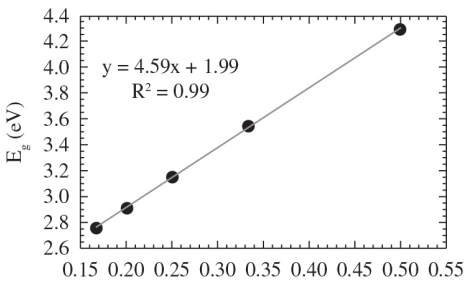

$1 / n$

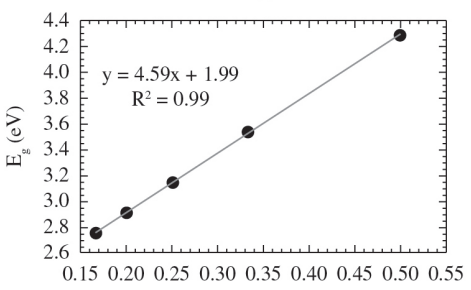

$1 / \mathrm{n}$

(1)

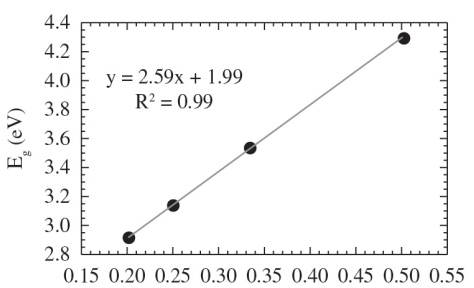

$1 / \mathrm{n}$

(o)

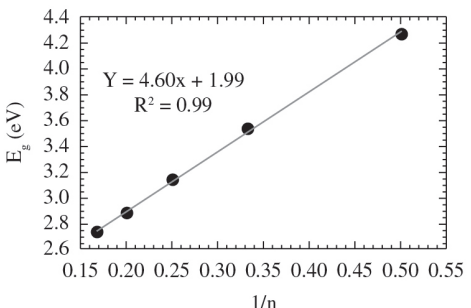

(r)

Figure 2. Extrapolation graphs for electronic properties of studied cases: (a) HOMO, (b) LUMO and (c) $\mathrm{E}_{\mathrm{g}}$ energies for methyl side chains, (d) HOMO, (e) LUMO and (f) $\mathrm{E}_{\mathrm{g}}$ energies for ethyl side chains, (g) HOMO, (h) LUMO and (i) $\mathrm{E}_{\mathrm{g}}$ energies for propyl side chains, (j) HOMO, (k) LUMO and (1) $\mathrm{E}_{\mathrm{g}}$ energies for butyl side chains, (m) HOMO, (n) LUMO and (o) $\mathrm{E}_{\mathrm{g}}$ energies for pentyl side chains, and (p) HOMO, (q) LUMO and (r) $\mathrm{E}_{\mathrm{g}}$ energies for hexyl side chains. 
Table 2. Values obtained for $\mathrm{E}_{\mathrm{g}}, \mathrm{E}_{\mathrm{vert}}$, and $\mathrm{E}_{\mathrm{b}}$ for six monomeric units of P3HT and different side chains.

\begin{tabular}{cccccc}
\hline & & TD-DFT & \multicolumn{2}{c}{ ZINDO/CIS } \\
\hline Side Chain Type & $\mathbf{E}_{\mathbf{g}}(\mathbf{e V})$ & $\mathbf{E}_{\text {vert }}(\mathbf{e V})$ & $\mathbf{E}_{\mathbf{b}}(\mathbf{e V})$ & $\mathbf{E}_{\text {vert }}(\mathbf{e V})$ & $\mathbf{E}_{\mathbf{b}}(\mathbf{e V})$ \\
\hline Methyl & 2.75 & 2.49 & 0.26 & 2.22 & 0.53 \\
Ethyl & 2.77 & 2.48 & 0.29 & 2.26 & 0.51 \\
Propyl & 2.76 & 2.47 & 0.29 & 2.26 & 0.50 \\
Butyl & 2.76 & 2.47 & 0.29 & 2.26 & 0.50 \\
Pentyl & 2.75 & 2.47 & 0.28 & 2.26 & 0.49 \\
Hexyl & 2.75 & 2.47 & 0.28 & 2.26 & 0.49 \\
\hline
\end{tabular}

in this study agree with those estimated for the calculation tools adopted here.

As can be seen from Table 1, the values obtained for polymers with different side chains have slightly different values. Among the factors that can influence these properties, withdrawing or donating electrons from/to the main chain by a substituent is one the most important ${ }^{14,19}$. These effects can move the position of HOMO and LUMO levels, depending on the amount of charge in the main chain $^{19}$. The alkyl groups can donate electrons by both induction and resonance ${ }^{45}$, thus causing changes in the electronic levels of the polymer. The intensity of this effect can be accounted for by the Hammett constants. Methyl and ethyl groups have slightly different values compared to the other alkyl groups studied here ${ }^{46}$. This suggests that no changes in electronic properties would be observed, owing to charge donation for groups larger than ethyl.

Structures with groups larger than ethyl have an approximately constant value for HOMO and LUMO; however, the values found for structures with the ethyl group were the closest to the experimental value. The structure with the methyl group shows the closest value for $\mathrm{E}_{\mathrm{g}}$, which explains why substitutions of long alkyl side chains with methyl groups show good results, as reported in the literature ${ }^{17,18}$. With groups larger than methyl, the value of $\mathrm{E}_{\mathrm{g}}$ is essentially unchanged. Thus, the values obtained for structures with the ethyl group have the smallest deviations for HOMO and LUMO, but for groups larger than ethyl we did not notice significant changes. The results suggest that alkyl groups with more than two carbons promote a charge distribution in the polymer backbone, so that electronic levels do not show significant variations. Such differences may be due to interactions between the neighboring side chains that can modify the charge distribution in the polymer, suggesting that for groups larger than ethyl these interactions would be stabilized.

Table 2 shows the results obtained for $\mathrm{E}_{\mathrm{b}}$ for oligomers with six monomer units of $\mathrm{P} 3 \mathrm{HT}$ and side chains ranging from methyl to hexyl. We present the values calculated by ZINDO/CIS and TD-DFT. According to experimental reports, the value of $\mathrm{E}_{\mathrm{b}}$ for $\mathrm{P} 3 \mathrm{HT}$ in the solid state can range from 0.2 to $0.7 \mathrm{eV}^{47-51}$ and decrease with increasing polymer chain length ${ }^{52}$. The results obtained for oligomers with six monomer units yield values that are within the range of values found experimentally. We note that the value of $\mathrm{E}_{\mathrm{b}}$ remained constant, independent of the type of side chain adopted, approximately $0.3 \mathrm{eV}$ and $0.5 \mathrm{eV}$ for TD-DFT and ZINDO/CIS calculations, respectively. So, the size of the alkyl side chain does not interfere significantly in $\mathrm{E}_{\mathrm{b}}$.

\section{Conclusions}

In theoretical studies of polymers, several structural approximations have been proposed, such as the oligomers approach and replacing long alkyl side chains with methyl groups. We conducted a study with the conjugated polymer P3HT to verify the influence of the length of the alkyl side chain on the electronic properties of the polymer.

The methodology adopted for the oligomer modeling proved to be reliable, since we found deviations for the HOMO, LUMO, and $\mathrm{E}_{\mathrm{g}}$ consistent with previous studies in the literature.

Variations in the electronic properties were observed according to the size of the alkyl side chain adopted in the theoretical calculations. We have verified that, with groups larger than ethyl, the results obtained for the HOMO, LUMO, and $\mathrm{E}_{\mathrm{g}}$ were constant, showing a saturation of such properties. Because of the similar values obtained for all the cases studied, the substitution of long ramifications by methyl groups may be plausible, but these do not take into account interactions between neighboring side chains. We did not notice significant changes for $\mathrm{E}_{\mathrm{b}}$ values of the structures with different side chain sizes.

Thus, we conclude that is possible to reduce the computational cost without compromising the quality of the results in studies with polymers containing long alkyl side chains. The use of methyl groups is a good approximation, but the smaller group that presents the best reproduction of the energies of the frontier electronic levels is the propyl group.

\section{Acknowledgments}

We would like to thank the Brazilian agency FAPESP (proc. 2012/21983-0) for financial support. This research was also supported by resources supplied by the Center for Scientific Computing (NCC/GridUNESP) of the São Paulo State University (UNESP). 


\section{References}

1. Bundgaard E and Krebs FC. Low band gap polymers for organic photovoltaics. Solar Energy Materials and Solar Cells. 2007; 91(11):954-985. http://dx.doi.org/10.1016/j. solmat.2007.01.015

2. Günes S, Neugebauer $\mathrm{H}$ and Sariciftci NS. Conjugated polymer-based organic solar cells. Chemical Reviews. 2007; 107(4):1324-1338. PMid:17428026. http://dx.doi.org/10.1021/ $\mathrm{cr} 050149 \mathrm{z}$

3. Melis C, Colombo L and Mattoni A. Self-Assembling of Poly(3-hexylthiophene). The Journal of Physical Chemistry C. 2011; 115(2):576-581. http://dx.doi.org/10.1021/jp109175b

4. Dag S and Wang L-W. Packing structureF of poly(3hexylthiophene) crystal: ab initio and molecular dynamics studies. The Journal of Physical Chemistry B. 2010; 114(18):5997-6000. PMid:20405875. http://dx.doi. org/10.1021/jp1008219

5. Maillard A and Rochefort A. Structural and electronic properties of poly(3-hexylthiophene) $\pi$-stacked crystals. Physical Review B. 2009; 79(11):115207. http://dx.doi. org/10.1103/PhysRevB.79.115207

6. He M, Ge J, Fang M, Qiu F and Yang Y. Fabricating polythiophene into highly aligned microwire film by fast evaporation of its whisker solution. Polymer. 2010; 51(10):2236-2243. http:// dx.doi.org/10.1016/j.polymer.2010.02.049

7. Kayunkid N, Uttiya S and Brinkmann M. Structural model of regioregular poly(3-hexylthiophene) obtained by electron diffraction analysis. Macromolecules. 2010; 43(11):4961-4967. http://dx.doi.org/10.1021/ma100551m

8. Batagin-Neto A, Oliveira EF, Graeff CFO and Lavarda FC. Modelling polymers with side chains: MEH-PPV and P3HT Molecular Simulation. 2013; 39(4):309-321. http://dx.doi.org /10.1080/08927022.2012.724174

9. Oliveira EF, Camilo A Jr, Silva-Filho LC and Lavarda FC. Effect of chemical modifications on the electronic structure of poly(3-hexylthiophene). Journal of Polymer Science Part B: Polymer Physics. 2013; 51(10):842-846. http://dx.doi. org/10.1002/polb.23274

10. Oliveira EF and Lavarda FC. Structure of P3HT in the solid state. Journal of Polymer Science Part B: Polymer Physics. 2013; 51(18):1350-1354. http://dx.doi.org/10.1002/polb.23338

11. Lan Y-K and Huang C-I. A theoretical study of the charge transfer behavior of the highly regioregular poly-3hexylthiophene in the ordered state. The Journal of Physical Chemistry B. 2008; 112(47):14857-14862. PMid:18973359. http://dx.doi.org/10.1021/jp806967x

12. Zade $\mathrm{S}$ and Bendikov M. From oligomers to polymers: Convergence in the HOMO-LUMO gaps of conjugated oligomers. Organic Letters. 2006; 8(23): 5243-5246. PMid:17078688. http://dx.doi.org/10.1021/o1062030y

13. Kanal IY, Owens SG, Bechtel JS and Hutchison GR. Efficient computational screening of organic polymer photovoltaics. The Journal of Physical Chemistry Letters. 2013; 4(10):1613-1623. http://dx.doi.org/10.1021/jz400215j

14. Gierschner J, Cornil J and Egelhaaf H. Optical bandgaps of $\pi$-conjugated organic materials at the polymer limit: experiment and theory. Advanced Materials. 2007; 19(2):179-191. http:// dx.doi.org/10.1002/adma.200600277

15. Zade S, Zamoshchik N and Bendikov M. From short conjugated oligomers to conjugated polymers. Lessons from studies on long conjugated oligomers. Accounts of Chemical Research. 2010; 44(1):14-24. PMid:20942477. http://dx.doi.org/10.1021/ ar1000555
16. Yang S, Olishevski P and Kertesz M. Bandgap calculations for conjugated polymers. Synthetic Metals. 2004; 141(1-2):171177. http://dx.doi.org/10.1016/j.synthmet.2003.08.019

17. Zhuang W, Lundin A and Andersson MR. Computational modelling of donor-acceptor conjugated polymers through engineered backbone manipulations based on a thiophenequinoxaline alternating copolymer. Journal of Materials Chemistry A. 2014; 2(7):2202-2212. http://dx.doi.org/10.1039/ c3ta14456a

18. Medina BM, Vooren AV, Brocorens P, Gierschner J, Shkunov $\mathrm{M}$, Heeney $\mathrm{M}$ et al. Electronic structure and charge-transport properties of polythiophene chains containing thienothiophene units: a joint experimental and theoretical study. Chemistry of Materials. 2007; 19(20):4949-4956. http://dx.doi.org/10.1021/ cm071279m

19. Roncali J. Molecular engineering of the band gap of $\pi$-conjugated systems: facing technological applications. Macromolecular Rapid Communications. 2007; 28(17):17611775. http://dx.doi.org/10.1002/marc.200700345

20. Blom PWM, Mihailetchi VD, Koster LJA and Markov DE Device Physics of Polymer: Fullerene Bulk Heterojunction Solar Cells. Advanced Materials. 2007; 19(12):1551-1566. http://dx.doi.org/10.1002/adma.200601093

21. Lee S, Yeo J-S, Ji Y, Cho C, Kim D-Y, Na S-I et al. Flexible organic solar cells composed of P3HT:PCBM using chemically doped graphene electrodes. Nanotechnology. 2012; 23(34):344013/1-344013/6. PMid:22885537. http://dx.doi. org/10.1088/0957-4484/23/34/344013

22. Ameri T, Min J, Li N, Machui F, Baran D, Forster M et al Performance enhancement of the P3HT/PCBM solar cells through NIR sensitization using a small-bandgap polymer Advanced Energy Materials. 2012; 2(10):1198-1202. http:// dx.doi.org/10.1002/aenm.201200219

23. Vohra V, Campoy-Quiles M, Garriga $\mathbf{M}$ and Murata $\mathrm{H}$ Organic solar cells based on nanoporous P3HT obtained from self-assembled P3HT:PS templates. Journal of Materials Chemistry. 2012; 22(37):20017-20025. http://dx.doi. org/10.1039/c2jm32639f

24. Oh SH, Heo SJ, Yang JS and Kim HJ. Effects of ZnO Nanoparticles on P3HT:PCBM Organic Solar Cells with DMFModulated PEDOT:PSS Buffer Layers. ACS Applied Materials \& Interfaces. 2013; 5(22):11530-11534. PMid:24175740. http://dx.doi.org/10.1021/am4046475

25. Parr RG and Yang W. Density-functional theory. In: Parr RG and Yang W. Density-functional theory of atoms and molecules. New York: Oxford University Press; 1989. p. 47-66.

26. Stewart JJP. Optimization of parameters for semiempirical methods V: Modification of NDDO approximations and application to 70 elements. Journal of Molecular Modeling. 2007; 13(12):1173-1213. PMid:17828561 PMCid:PMC2039871. http://dx.doi.org/10.1007/s00894007-0233-4

27. Stewart JJP. MOPAC: molecular orbital package. Stewart Computational Chemistry; 2012. Available from: $<$ http://www. openmopac.net/MOPAC2012.html .

28. Hiorns RC, Iratçabal P, Bégué D, Khoukh A, De Bettignies R, Leroy $\mathrm{J}$ et al. Alternatively linking fullerene and conjugated polymers. Journal of Polymer Science Part A: Polymer Chemistry. 2009; 47(9):2304-2317. http://dx.doi.org/10.1002/ pola.23311

29. Hiorns RC, Cloutet E, Ibarboure E, Vignau L, Lemaitre $\mathrm{N}$, Guillerez $\mathrm{S}$ et al. Main-chain fullerene polymers for photovoltaic devices. Macromolecules. 2009; 42(10):35493558. http://dx.doi.org/10.1021/ma900279a 
30. Stephens PJ, Devlin FJ, Chablowski CF and Frisch MJ. $\mathrm{Ab}$ Initio calculation of vibrational absorption and circular dichroism spectra using density functional force fields. Journal of Physical Chemistry. 1994; 98(45):11623-11627. http:// dx.doi.org/10.1021/j100096a001

31. Schmidt MW, Baldridge KK, Boatz JA, Elbert ST, Gordon MS, Jensen JH et al. General atomic and molecular electronic structure system. Journal of Computational Chemistry. 1993; 14(11):1347-1363. http://dx.doi.org/10.1002/jcc.540141112

32. Hehre WJ. Quantum chemical models. In: Hehre WJ. A guide to molecular mechanics and quantum chemical calculations. Irvine: Wavefunction; 2003. p. 40-46.

33. Li G, Shu R and Yang Y. Polymer solar cells. Nature Photonics. 2012; 6(3):153-161. http://dx.doi.org/10.1038/ nphoton.2012.11

34. Dkhissi A, Ouhib F, Chaalane A, Hiorns RC, Dagron-Lartigau $\mathrm{C}$, Iratcabal $\mathrm{P}$ et al. Theoretical and experimental study of low band gap polymers for organic solar cells. Physical Chemistry Chemical Physics. 2012; 14(16):5613-5619. PMid:22426037. http://dx.doi.org/10.1039/c2cp40170c

35. Zhu L, Liping YY and Shuai CZ. Exciton binding energy of electronic polymers: A first principles study. Journal of Theoretical and Computational Chemistry. 2008; 7(4):517-530. http://dx.doi.org/10.1142/S0219633608003939

36. Levine IN. Semiempirical and molecular-mechanics treatments of molecules. In: Levine IN. Quantum chemistry. 5th ed. New Jersey: Prentice Hall; 2000. p. 655-657. PMid:11056829.

37. Lewars E. Semiempirical calculations. In: Lewars E. Computational chemistry: introduction to the theory and applications of molecular and quantum mechanics. 2nd ed. New York: Kluwer Academic Publishers; 2004. p. 398-400.

38. Leach A. Advanced ab initio methods, density functional theory and solid-state quantum mechanics. In: Leach A. Molecular modelling: principles and applications. 2nd ed. New Jersey: Prentice Hall; 2001. p. 111-113.

39. Jensen F. Electron correlation methods. In: Jensen F. Introduction to computational chemistry. 2nd ed. New Jersey: John Wiley \& Sons; 2007. p. 133-144.

40. Neese F. ORCA: an ab initio, DFT and semiempirical SCF-MO. 2010. Available from: <http://www.thch.uni-bonn.de/tc/orca $>$.

41. Marques MAL and Gross EKU. Time-dependent density functional theory. Annuals Reviews Physical Chemistry. 2004; 55:427-455. PMid:15117259. http://dx.doi.org/10.1146/ annurev.physchem.55.091602.094449
42. Meier H, Stalmach U and Kolshorn H. Effective conjugation length and UV/vis spectra of oligomers. Acta Polymerica. 1997; 48(9):379-384. http://dx.doi.org/10.1002/actp.1997.010480905

43. Yongfang L. Molecular design of photovoltaic materials for polymer solar cells: Toward suitable electronic energy levels and broad absorption. Accounts of Chemical Research. 2012; 45(5):723-733. PMid:22288572. http://dx.doi.org/10.1021/ ar2002446

44. McCormick TM, Bridges CR, Carrera EI, DiCarmine PM, Gibson GL, Hollinger J et al. Conjugated polymers: Evaluating DFT methods for more accurate orbital energy modeling. Macromolecules. 2013; 46(10): 3879-3886. http://dx.doi. org/10.1021/ma4005023

45. McMurry JE. Polar covalent bonds; acids and bases. In: McMurry JE. Organic chemistry. 8th ed. Stanford: Cenage Learning; 2004. p. 34-42.

46. Carey F and Sundberg RJ. Structural effects on stability and reactivity. In: Carey F and Sundberg RJ. Advanced organic chemistry. Part A: structure and mechanisms. 5th ed. New York: Springer; 2007. p. 335-344.

47. Deibel C, Mack D, Gorenflot J, Schöll A, Krause S, Reinert $F$ et al. Energetics of excited states in the conjugated polymer poly(3-hexylthiophene). Physical Review B. 2010; 81(8):085202. http://dx.doi.org/10.1103/PhysRevB.81.085202

48. van der Horst J-W, Bobbert PA, Michels MAJ and Bässler H. Calculation of excitonic properties of conjugated polymers using the Bethe-Salpeter equation. Journal of Chemical Physics. 2001; 114(15):6950-6957. http://dx.doi. org/10.1063/1.1356015

49. Dissanayake NM and Zhong Z. Unexpected Hole Transfer Leads to High Efficiency Single-Walled Carbon Nanotube Hybrid Photovoltaic. Nano Letters. 2011; 11(1):286-290. PMid:21117704. http://dx.doi.org/10.1021/nl103879b

50. Frisch J, Schubert M, Preis E, Rabe JP, Neher D, Scherf U et al. Full electronic structure across a polymer heterojunction solar cell. Journal of Materials Chemistry. 2012; 22(10):4418-4424. http://dx.doi.org/10.1039/c1jm14968g

51. Heibera MC and Dhinojwalab A. Dynamic Monte Carlo modeling of exciton dissociation in organic donor-acceptor solar cells. The Journal of Chemical Physics. 2012; 137(1):014903. PMid:22779679. http://dx.doi.org/10.1063/1.4731698

52. Knupfer M. Exciton binding energies in organic semiconductors. Applied Physics A. 2003; 77(5):623-626. http://dx.doi. org/10.1007/s00339-003-2182-9 